\title{
Sublobectomy versus Lobectomy for stage IA (T1a) non-small-cell lung cancer: a meta-analysis study
}

Yaxin Liư ${ }^{2}$, Cheng Huang ${ }^{1}$, Hongsheng Liu', Yeye Chen ${ }^{1}$ and Shanqing $\mathrm{Li}^{1,2^{*}}$

\begin{abstract}
Background: Although lobectomy is considered the standard surgical treatment for the majority of patients with non-small-cell lung cancer (NSCLC), the operation project for patients with stage IA NSCLC (T1a, tumor diameter $\leq 2 \mathrm{~cm}$ ) remains controversial. Sublobectomy is appropriate only in certain patients as many doctors consider it to be overtreatment. We evaluated the five-year overall survival rate of sublobectomy and lobectomy for stage IA NSCLC (T1a, tumor diameter $\leq 2 \mathrm{~cm}$ ) through a meta-analysis.

Methods: The five-year overall survival rate (OS) of stage IA (T1a) NSCLC after sublobectomy (including wedge resection and segmentectomy) and lobectomy were compared. We also compared the OS of stage IA (T1a) NSCLC after segmentectomy and lobectomy. The log (hazard ratio, In (HR)) and its standard error (SE) were used as the outcome measure for data combining.

Results: There were 12 eligible studies published between 1994 and 2013 in which the total number of participants was 18,720 . When compared to lobectomy, there was a statistically significant difference of sublobectomy on OS of stage IA (T1a) NSCLC patients (HR 1.38; 95\% confidence interval (95\% Cl), 1.19 to 1.61; $P$ $<0.0001)$. For the comparison between segmentectomy and lobectomy, there was also a statistically significant difference of segmentectomy alone on OS of stage IA (T1a) NSCLC patients (HR 1.48; 95\% Cl: 1.27 to 1.73; P $<0.00001)$
\end{abstract}

Conclusions: We have concluded that in stage IA (T1a) patients sublobectomy, including segmentectomy and wedge resection, causes a lower survival rate than lobectomy.

Keywords: Sublobectomy, Lobectomy, Non-Small-Cell lung Cancer, Meta-analysis, Overall Survival (OS)

\section{Background}

With the wide use of high-resolution computed tomography (CT) and low-dose helical CT in lung cancer screening, an increasing number of non-small-cell lung cancers (NSCLCs) are diagnosed at the early T1 stage. Considering the relatively good prognosis of $\mathrm{T} 1$ stage NSCLC, many surgeons began to question the necessity of a total lobectomy in the management of patients with such small lesions [1-3]. As an alternative, sublobectomy, including wedge resection and segmentectomy,

\footnotetext{
* Correspondence: pumchlsq@163.com

'Department of Thoracic Surgery, Peking Union Medical College Hospital, Shuaifuyuan No.1 Dongcheng District, Beijing 100730, China

${ }^{2}$ Graduate School of Peking Union Medical College, Chinese Academy of Medical Sciences, Shuaifuyuan No.1 Dongcheng District, Beijing 100730,
} China

\section{Biomed Central}

(c) 2014 Liu et al.; licensee BioMed Central Ltd. This is an Open Access article distributed under the terms of the Creative Commons Attribution License (http://creativecommons.org/licenses/by/2.0), which permits unrestricted use, distribution, and reproduction in any medium, provided the original work is properly credited. The Creative Commons Public Domain Dedication waiver (http://creativecommons.org/publicdomain/zero/1.0/) applies to the data made available in this article unless otherwise stated. reduces the length of surgery, thus resulting in fewer complications and shorter hospitalization time $[4,5]$. This procedure is only acceptable in cases with a tumor size of less than $2 \mathrm{~cm}$, according to the recommendation from the National Comprehensive Cancer Network (NCCN) Clinical Practice Guideline in Oncology for NSCLC, version 2.2013, however the outcome of sublobectomy is still controversial.

In 1995, the Lung Cancer Study Group (LCSG) compared the outcomes of sublobar with lobar resection in a randomized trial and demonstrated that patients with sublobar resection had a lower survival rate [6]. The same results have been published in some nonrandomized trials [7], which examine a comparison between wedge resection alone and lobectomy. However, 
several other studies have demonstrated that limited resection was not inferior to lobectomy regarding prognosis in patients with small and peripheral NSCLC [8]. The results from the LCSG have been further challenged by several retrospective studies, which have suggested that limited resection might be equally effective in the treatment of stage IA (T1a) patients with a tumor size of less than $2 \mathrm{~cm}$ compared with lobectomy, particularly among elderly patients [9-12].

To compare the outcome of sublobectomy and lobectomy, Nakamura et al. conducted a meta-analysis of published studies between 1970 and 2004 in 2005 [10]. The analysis indicated that the outcome of limited resection was comparable to lobectomy in patients with stage I lung cancer. Since then, several large clinical trial results have been published. In 2012, Fan et al. conducted another meta-analysis of published studies between 1990 and 2010 which indicated that for stage I patients, sublobectomy causes a lower survival rate than lobectomy, while for stage IA (T1a) patients, sublobectomy produces a similar survival rate to lobectomy [13]. Taking all these into consideration, we felt it necessary to reevaluate the efficacy of sublobectomy in patients with stage IA (T1a) NSCLC (tumor diameter $\leq 2 \mathrm{~cm}$ ). We therefore collected the updated data from published studies between 1994 and 2013 and evaluated the effectiveness of sublobectomy compared to lobectomy for stage IA (T1a) NSCLC (tumor diameter $\leq 2 \mathrm{~cm}$ ) through a meta-analysis of these studies.

\section{Methods}

\section{Identification of studies}

We searched PubMed using the strategy of (limited resection [Title/Abstract] OR (sublobar resection [Title/ Abstract]) OR (segmentectomy [Title/Abstract]) OR (wedge resection [Title/Abstract]) AND (lung [Title/Abstract] OR pulmonary [Title/Abstract]) AND (cancer [Title/Abstract]) OR (carcinoma [Title/Abstract]) AND (lobectomy [Title/Abstract]). We also searched Embase by the strategy of 'limited resection': ab OR 'sublobar resection': ab OR segmentectomy: ab OR 'wedge resection': ab AND (lung: ab OR pulmonary: ab) AND (cancer: ab OR carcinoma: ab) AND lobectomy: ab. The citations of all retrieved articles were checked to identify any other potentially relevant publications. The studies in the search results were selected based on the inclusion and exclusion criteria. The inclusion criteria were: (i) outcomes of interest include overall survival rate (OS) (ii) articles were peer-reviewed, published, and original articles (iii) information was described in the article on how the hazard ratio (HR) and standard error (SE) can be calculated (iv) study subjects had to be limited to clinical stage IA (T1a) patients, (v) patients were divided into lobectomy and sublobectomy, (vi) if the enrolled patients were from the same institutions and in the same period, only the most recently published data would be enrolled into the study. The exclusion criteria were: (i) letters to editor, case reports, reviews, and non-English articles (ii) patients were divided into segmentectomy and wedge resection. In recent studies, the definition of sublobectomy includes the wedge resection and segmentectomy. Some of the studies analyzed the survival of patients after wedge resection or anatomic segmentectomy separately, whereas some studies studied only the survival after sublobectomy. We enrolled studies in which we could collect survival data after sublobectomy versus lobectomy to further analyze the outcomes of these results.

\section{Statistical analysis}

The log (hazard ratio, ln (HR)) and its standard error (SE) were used as the outcome measure for data combination $[14,15]$. The SE was obtained as:

$\ln$ (upper $95 \%$ CI) - $\ln ($ lower $95 \%$ CI)/3:92

The $\ln (\mathrm{HR})$ and its SE were calculated from the reported data directly by $\mathrm{HR}$ and its $95 \% \mathrm{CI}$, or indirectly by reading and extracting from the Kaplan-Meier survival curve $[5,9,12,16-24]$. The heterogeneity of included studies was detected using the Cochran test. The publication bias was analyzed by Egger's methods [25]. The evidence of asymmetry was based on $P<1$. KaplanMeier curves were read by Origin version 9 www.originlab.com. The data combining the test of heterogeneity was conducted and analyzed using Review Manager Version 5.1 http://www.cochrane.org/.

\section{Results}

The total number of studies obtained from the searches were 1342 from PubMed and Embase. According to the inclusion and exclusion criteria, there were 12 eligible studies published between 1994 and 2013 [5,9,12,16-24]. All of these studies were retrospective studies. The characteristics of all the included clinical trials are listed in Table 1. The size of the cohorts varied from 72 to 5626, with a total number of 18720 patients. In the analysis, the sublobectomy group was the experimental group and the lobectomy group was chosen as the reference. There were a total of 12 studies involved in the analysis that compared the impact of sublobectomy and lobectomy on OS of Stage IA (T1a) NSCLC patients. The combined HR of OS was 1.38 (95\% CI, 1.19 to $1.61 ; P$ $<0.0001)$. The sublobectomy group was inferior to patients treated with lobectomy. The Cochran tests for heterogeneity showed that $\operatorname{tau}^{2}=0.03 ; \mathrm{chi}^{2}=30.57 \mathrm{df}=13$ $(P=0.004) ; \mathrm{I}^{2}=57 \%$, which suggested significant inconsistency; and so we choose to use the random method instead random effects models (Figure 1). There was no significant publication bias detected at the section of 
Table 1 General characteristics of the enrolled studies

\begin{tabular}{|c|c|c|c|c|c|c|c|}
\hline Study & Stage & Tumor size & Comparison & Outcome & Sample size & Sublobectomy & Lobectomy \\
\hline Koike et al. [5] & la & $\leq 2 \mathrm{~cm}$ & segmentectomy vs lobectomy & 5-year survival & 233 & 74 & 159 \\
\hline Okada et al. [9] & la & $\leq 2 \mathrm{~cm}$ & sublobectomy vs lobectomy & 5-year survival & 567 & 305 & 262 \\
\hline Whitson et al. [21] & la & $\leq 2 \mathrm{~cm}$ & segmentectomy vs lobectomy & 5-year survival & 5626 & 291 & 5335 \\
\hline Wolf et al. [18] & la & $\leq 2 \mathrm{~cm}$ & sublobectomy vs lobectomy & 5-year survival & 238 & 154 & 84 \\
\hline Kates et al. [24] & la & $\leq 1 \mathrm{~cm}$ & sublobectomy vs lobectomy & 5-year survival & 2064 & 688 & 1376 \\
\hline Okada et al. [23] & la & $\leq 2 \mathrm{~cm}$ & segmentectomy vs lobectomy & 5-year survival & 209 & 70 & 139 \\
\hline Okami et al. [22] & la & $\leq 2 \mathrm{~cm}$ & sublobectomy vs lobectomy & 5-year survival & 764 & 146 & 618 \\
\hline Warren and Faber [12] & la & $\leq 2 \mathrm{~cm}$ & segmentectomy vs lobectomy & 5-year survival & 72 & 38 & 34 \\
\hline Wisnivesky et al. [20] & la & $\leq 2 \mathrm{~cm}$ & sublobectomy vs lobectomy & 5-year survival & 1165 & 196 & 969 \\
\hline Wisnivesky et al. [19] & la & $\leq 2 \mathrm{~cm}$ & sublobectomy vs lobectomy & 5-year survival & 249 & 47 & 202 \\
\hline Yendamuri et al. (1987-1997) [17] & la & $\leq 2 \mathrm{~cm}$ & sublobectomy vs lobectomy & 5-year survival & 1961 & 469 & 1492 \\
\hline Yendamuri et al. (1998-2004) [17] & la & $\leq 2 \mathrm{~cm}$ & segmentectomy vs lobectomy & 5-year survival & 2691 & 150 & 2541 \\
\hline Yendamuri et al. (2005-2008) [17] & la & $\leq 2 \mathrm{~cm}$ & segmentectomy vs lobectomy & 5-year survival & 2761 & 162 & 2599 \\
\hline Zhong et al. [16] & la & $\leq 2 \mathrm{~cm}$ & segmentectomy vs lobectomy & 5-year survival & 120 & 39 & 81 \\
\hline
\end{tabular}

The sublobectomy group did not distinguish between segmentectomy and wedge resection. In the study of Yendamuri et al. in 2013 [17], three groups of data in different time periods were compared.

analysis (Figure 2). Taking the age into consideration, we reasoned that the prognosis might be different in time periods. To minimize this deviation we excluded all data from before 2000 and made a future comparison. As a result, there were only three studies involved, and unfortunately, the outcome showed no statistical significance (HR 1.38; 95\% CI, 0.95 to 2.00; $P=0.09$ ) (Figure 3). In order to avoid the interaction between wedge resection and segmentectomy, we also made a further comparison between the segmentectomy group alone and the lobectomy group (Figure 4). The combined HR of OS was 1.48 (95\% CI, 1.27 to $1.73 ; P<0.00001)$. The result is similar to that of the sublobectomy group. The Cochran tests for heterogeneity showed that $\mathrm{tau}^{2}=0.00 ; \mathrm{chi}^{2}=$ $3.97 \mathrm{df}=6(P=0.68) ; \mathrm{I}^{2}=0 \%$.

\section{Discussion}

There are three original prospective randomized clinical trials about the comparison between sublobectomy and lobectomy. The earliest one is written by Ginsberg and Rubinstein in 1995 [6] and was excluded because the group division did not conform to our study. The other two trials were launched by The National Cancer Institute (NCI) (CALGB 140503) in 2008 [13] and The Japan Clinical Oncology Group with the West Japan Oncology Group (JCOG0802/WJOG4607L) in 2009 [26]; both comparing the survival of lobectomy and sublobectomy for small peripheral non-small-cell lung cancer $(\leq 2 \mathrm{~cm})$. Neither study has finished to date.

Before these studies publish their final results and conclusions, we used meta-analysis to combine current

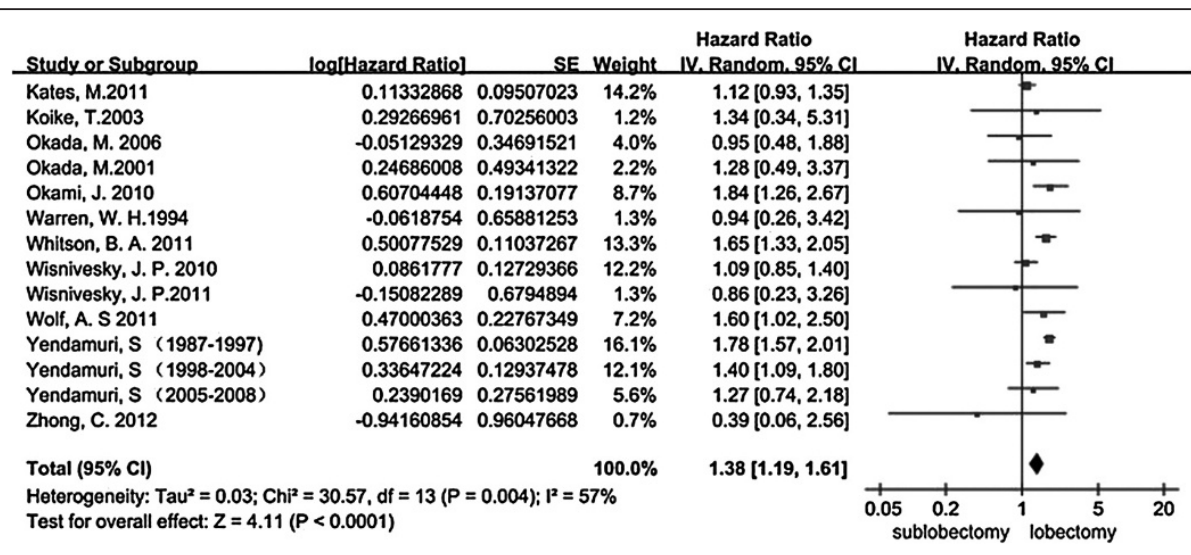

Figure 1 Forest plot of HR for OS impact of operative approach (sublobectomy versus lobectomy) of stage IA NSCLC patients. The combined HR displayed in this figure when compared with sublobectomy suggested that there was a significant benefit of lobectomy on OS of stage IA patients with tumors no larger than $2 \mathrm{~cm}$, (HR 1.38; 95\% Cl, 1.19 to 1.61; $P<0.0001)[5,9,12,16-24]$. Cl, confidence interval; df, degree of freedom; HR, hazard ratio, OS, overall survivalNSCLC,non-small cell lung cancer; SE, standard error 


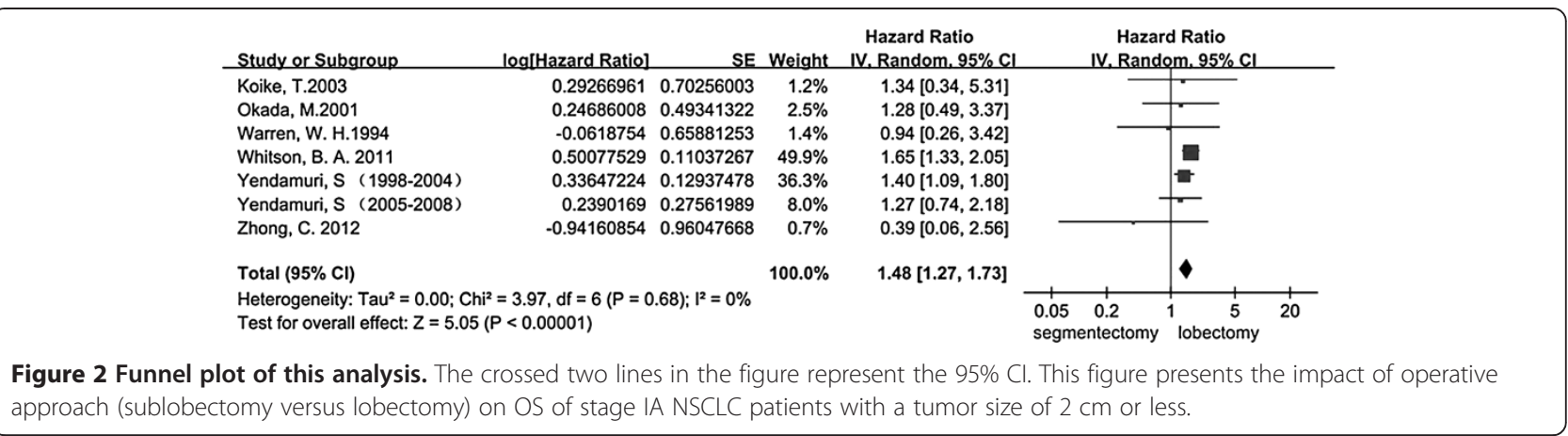

retrospective data. All the data included in our study were drawn from the retrospective studies. We found significant discrepancies among these studies for sample size, distribution of histological types, gender ratio, reasons for sublobectomy, and details of the operation. These differences might contribute to inter-study heterogeneity, therefore, the random model in RevMan was used for significant heterogeneities detection [27]. When considering the possible existence of publication bias among the enrolled studies, a test for publication bias was performed and no significant publication bias was detected after proper application of the above test.

The proper extent of pulmonary resection should achieve complete eradication of the malignancy and reduce the damage as much as possible. The operation project for patients with stage IA (T1a) NSCLC (tumor diameter $\leq 2 \mathrm{~cm}$ ) remains controversial and has been under debate for several years.

We analyzed the impact of sublobectomy and lobectomy on the OS of NSCLC patients with stage IA (T1a) (tumors $\leq 2 \mathrm{~cm}$ ). We found that the combined HR of OS was $1.38(95 \% \mathrm{CI}, 1.19$ to $1.61 ; P<0.0001)$. The

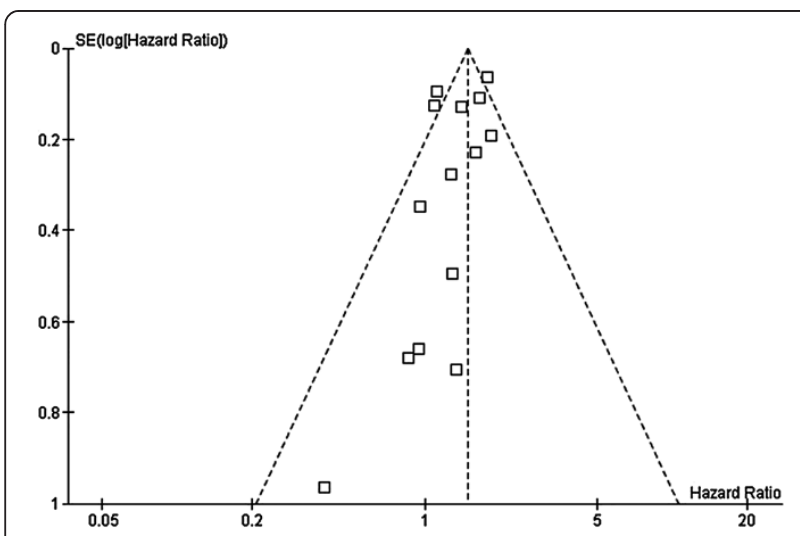

Figure 3 Forest plot of HR for OS impact of operative approach (sublobectomy versus lobectomy) of stage IA NSCLC patients with data after 2000. The combined HR displayed in this figure suggested there was no statistical significance between sublobectomy and lobectomy on OS (HR 1.38; $95 \% \mathrm{Cl}, 0.95$ to 2.00; $P=0.09)$. Cl, confidence interval; df, degree of freedom; HR, hazard ratio; OS, overall survival [16-18]. sublobectomy group was inferior to patients treated with the lobectomy. The segmentectomy group alone was similar to confirmed (HR 1.48, 95\% CI, 1.27 to 1.73 ; $P$ $<0.00001)$. However, with recent data (data after 2000), we did not get the same results in the comparison between sublobectomy and lobectomy groups; there was no statistical significance (HR 1.38; 95\% CI, 0.95 to 2.00; $P=0.09$ ). Since there were only three studies in this comparison, we could not draw a definite conclusion, however, there could be a correlation between good prognosis and sublobectomy.

There are some limitations of this study:. (i) We could not collect and analyze data about the chemotherapy and radiotherapy information which might affect the survival of some patients. (ii) We consider the clinical stage more significant than the pathological one in choosing a surgical method, however, most of the retrospective studies did not describe clearly whether the stage was clinical or pathological; (iii) We think that the comparison in patients who can tolerate the lobectomy should be more powerful, however, most studies did not separate the lobectomy tolerance group and nonlobectomy tolerance group; (iv) Most studies did not take systematic or sampling lymphadenectomy into consideration, which could have an influence on the fiveyear survival rate; (v) Studies on the field of comparison between sublobectomy and lobectomy for stage IA (T1a) NSCLC have not taken the appearance on CT (pure solid, pure ground grass opacity (GGO), and part solid + GGO.) into consideration, which is quite important to the prognosis; and (vi) Retrospective studies could have some bias due to reasons which have been mentioned before.

\section{Conclusions}

The current meta-analysis disclosed that sublobectomy (including wedge resection and segmentectomy) causes lower OS in stage IA (T1a) NSCLC patients. We suggest that lobectomy is the best optimal choice, which is in line with the recommendation from National Comprehensive Cancer Network (NCCN) Clinical Practice Guideline in Oncology for NSCLC version 2.2013. 


\begin{tabular}{|c|c|c|c|c|c|c|}
\hline Study or Subgroup & log[Hazard Ratio] & SE & Weight & $\begin{array}{l}\text { Hazard Ratio } \\
\text { IV. Random, } 95 \% \mathrm{CI}\end{array}$ & $\begin{array}{c}\text { Hazard Ratio } \\
\text { IV. Random, } 95 \% \mathrm{CI}\end{array}$ & \\
\hline Wolf, A. S 2011 & 0.47000363 & 0.22767349 & $55.5 \%$ & $1.60[1.02,2.50]$ & 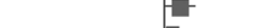 & \\
\hline Yendamuri, S (2005-2008) & 0.2390169 & 0.27561989 & $40.6 \%$ & $1.27[0.74,2.18]$ & & \\
\hline Zhong, C. 2012 & -0.94160854 & 0.96047668 & $3.9 \%$ & $0.39[0.06,2.56]$ & & \\
\hline Total $(95 \% \mathrm{Cl})$ & & & $100.0 \%$ & $1.38[0.95,2.00]$ & & \\
\hline $\begin{array}{l}\text { Heterogeneity: } \mathrm{Tau}^{2}=0.01 ; \\
\text { Test for overall effect: } Z=1.6\end{array}$ & $\begin{array}{l}=2.24, d f=2(P=0 \\
P=0.09)\end{array}$ & $0.33) ; 1^{2}=11 \%$ & & & $\begin{array}{cccc}0.01 & 0.1 & 1 & 10 \\
\text { sublobectomy } & \text { lobectomy }\end{array}$ & 100 \\
\hline
\end{tabular}

Figure 4 Forest plot of HR for OS impact of operative approach (segmentectomy versus lobectomy) of stage IA NSCLC patients. The combined HR displayed in this figure, compared with segmentectomy, suggest that there was a significant benefit of lobectomy on OS of stage IA patients with tumors no larger than $2 \mathrm{~cm}$ (HR 1.48; 95\% Cl, 1.27 to 1.73; $P<0.00001)$ ]. Cl, confidence interval; df, degree of freedom; HR, hazard ratio; OS, overall survival $[5,9,12,16,17,21]$.

Considering the heterogeneity among studies and all data from retrospective studies, the results of the metaanalysis should be interpreted with caution and the data of studies previously mentioned should be supplemented with a further analysis in the coming future.

\section{Competing interests}

The authors declare that they have no competing interests.

\section{Authors' contributions}

$Y L$ participated in the literature searching and performed the statistical analysis, and drafted the manuscript. $\mathrm{CH}$ participated in the literature searching. $\mathrm{HL}$ and $\mathrm{YC}$ participated in the design of the study. SL conceived of the study, and participated in its design and coordination and helped to draft the manuscript. All authors read and approved the final manuscript.

\section{Acknowledgements}

We would like thanks to Zhichao Lai and Qianqian Pan for providing us assistance in the statistical calculation and data management respectively. This work was supported by the Key Grant Project of the Chinese Ministry of Education (NO.311037).

Received: 31 October 2013 Accepted: 11 April 2014

Published: 1 May 2014

\section{References}

1. Okada M, Nishio W, Sakamoto T, Uchino K, Yuki T, Nakagawa A, Tsubota N: Effect of tumor size on prognosis in patients with non-small cell lung cancer: the role of segmentectomy as a type of lesser resection. J Thorac Cardiovasc Surg 2005, 129:87-93.

2. Bando T, Yamagihara K, Ohtake Y, Miyahara R, Tanaka F, Hasegawa S, Inui K, Wada $\mathrm{H}$ : A new method of segmental resection for primary lung cancer: intermediate results. Eur J Cardiothorac Surg 2002, 21:894-899.

3. Lewis RJ: The role of video-assisted thoracic surgery for carcinoma of the lung: wedge resection to lobectomy by simultaneous individual stapling. Ann Thorac Surg 1993, 56:762-768.

4. El-Sherif A, Gooding WE, Santos R, Pettiford B, Ferson PF, Fernando HC, Urda SJ, Luketich JD, Landreneau RJ: Outcomes of sublobar resection versus lobectomy for stage I non-small cell lung cancer: a 13-year analysis. Ann Thorac Surg 2006, 82:408-416.

5. Koike T, Yamato Y, Yoshiya K, Shimoyama T, Suzuki R: Intentional limited pulmonary resection for peripheral T1 N0 M0 small-sized lung cancer. $J$ Thorac Cardiovasc Surg 2003, 125:924-928.

6. Ginsberg RJ, Rubinstein LV: Randomized trial of lobectomy versus limited resection for T1 N0 non-small cell lung cancer. Ann Thorac Surg 1995, 60:615-623.

7. Landreneau RJ, Sugarbaker DJ, Mack MJ, Hazelrigg SR, Luketich JD, Fetterman L, Liptay MJ, Bartley S, Boley TM, Keenan RJ: Wedge resection versus lobectomy for stage I (T1 N0 M0) non-small-cell lung cancer. J Thorac Cardiovasc Surg 1997, 113:691-700.

8. Kodama K, Doi O, Higashiyama M, Yokouchi H: Intentional limited resection for selected patients with $\mathrm{T} 1 \mathrm{~N} 0 \mathrm{M} 0$ non-small-cell lung cancer: a single-institution study. J Thorac Cardiovasc Surg 1997, 114:347-353.
9. Okada M, Koike T, Higashiyama M, Yamato Y, Kodama K, Tsubota N: Radical sublobar resection for small-sized non-small cell lung cancer: a multicenter study. J Thorac Cardiovasc Surg 2006, 132:769-775.

10. Nakamura H, Kawasaki N, Taguchi M, Kabasawa K: Survival following lobectomy vs limited resection for stage I lung cancer: a meta-analysis. Br J Cancer 2005, 92:1033-1037.

11. Sugarbaker DJ, Strauss GM: Extent of surgery and survival in early lung carcinoma: implications for overdiagnosis in stage IA nonsmall cell lung carcinoma. Cancer 2000, 89:2432-2437.

12. Warren $\mathrm{WH}$, Faber LP: Segmentectomy versus lobectomy in patients with stage I pulmonary carcinoma: five-year survival and patterns of intrathoracic recurrence. J Thorac Cardiovasc Surg 1994, 107:1087-1093. discussion 1093-1084.

13. Fan J, Wang L, Jiang GN, Gao W: Sublobectomy versus lobectomy for stage I non-small-cell lung cancer, a meta-analysis of published studies. Ann Surg Oncol 2012, 19:661-668.

14. Parmar MK, Torri V, Stewart L: Extracting summary statistics to perform meta-analyses of the published literature for survival endpoints. Stat Med 1998, 17:2815-2834.

15. Tierney JF, Stewart LA, Ghersi D, Burdett S, Sydes MR: Practical methods for incorporating summary time-to-event data into meta-analysis. Trials 2007, 8:16.

16. Zhong C, Fang W, Mao T, Yao F, Chen W, Hu D: Comparison of thoracoscopic segmentectomy and thoracoscopic lobectomy for smallsized stage IA lung cancer. Ann Thorac Surg 2012, 94:362-367.

17. Yendamuri S, Sharma R, Demmy M, Groman A, Hennon M, Dexter E, Nwogu C, Miller A, Demmy T: Temporal trends in outcomes following sublobar and lobar resections for small $(</=2 \mathrm{~cm})$ non-small cell lung cancers-a surveillance epidemiology end results database analysis. J Surg Res 2013, 183:27-32.

18. Wolf AS, Richards WG, Jaklitsch MT, Gill R, Chirieac LR, Colson YL, Mohiuddin K, Mentzer SJ, Bueno R, Sugarbaker DJ, Swanson SJ: Lobectomy versus sublobar resection for small ( $2 \mathrm{~cm}$ or less) non-small cell lung cancers. Ann Thorac Surg 2011, 92:1819-1823. discussion 1824-1815.

19. Wisnivesky JP, Yip R, Hanaoka T, Bauer T, Inderbitzi R, Ayer R, Kohman L, Sheppard B, Thurer R, Smith MV: Limited resection for the treatment of screen-detected stage ia lung cancer. Am J Respir Crit Care Med 2011, 183: A5394.

20. Wisnivesky JP, Henschke CI, Swanson S, Yankelevitz DF, Zulueta J, Marcus S, Halm EA: Limited resection for the treatment of patients with stage IA lung cancer. Ann Surg 2010, 251:550-554.

21. Whitson BA, Groth SS, Andrade RS, Maddaus MA, Habermann EB, D'Cunha J: Survival after lobectomy versus segmentectomy for stage I non-small cell lung cancer: a population-based analysis. Ann Thorac Surg 2011, 92:1943-1950.

22. Okami J, Ito Y, Higashiyama M, Nakayama T, Tokunaga T, Maeda J, Kodama K: Sublobar resection provides an equivalent survival after lobectomy in elderly patients with early lung cancer. Ann Thorac Surg 2010, 90:16511656.

23. Okada M, Yoshikawa K, Hatta T, Tsubota N: Is segmentectomy with lymph node assessment an alternative to lobectomy for non-small cell lung cancer of $2 \mathrm{~cm}$ or smaller? Ann Thorac Surg 2001, 71:956-960.

24. Kates M, Swanson S, Wisnivesky JP: Survival following lobectomy and limited resection for the treatment of stage I non-small cell lung cancer $\leq 1 \mathrm{~cm}$ in SizeA review of SEER data. Chest J 2011, 139:491-496. 
25. Egger M, Smith GD, Schneider M, Minder C: Bias in meta-analysis detected by a simple, graphical test. BMJ 1997, 315:629-634.

26. Nakamura K, Saji H, Nakajima R, Okada M, Asamura H, Shibata T, Nakamura $\mathrm{S}$, Tada $\mathrm{H}$, Tsuboi M: A phase III randomized trial of lobectomy versus limited resection for small-sized peripheral non-small cell lung cancer (JCOG0802/WJOG4607L). Jap J Clin Oncol 2010, 40:271-274.

27. Wang L, Shao Z-M: Cyclin e expression and prognosis in breast cancer patients: a meta-analysis of published studies. Cancer Invest 2006, 24:581587.

doi:10.1186/1477-7819-12-138

Cite this article as: Liu et al:: Sublobectomy versus Lobectomy for stage IA (T1a) non-small-cell lung cancer: a meta-analysis study. World Journal of Surgical Oncology 2014 12:138.

\section{Submit your next manuscript to BioMed Central and take full advantage of:}

- Convenient online submission

- Thorough peer review

- No space constraints or color figure charges

- Immediate publication on acceptance

- Inclusion in PubMed, CAS, Scopus and Google Scholar

- Research which is freely available for redistribution 